\title{
Intensive Lifestyle Counselling Intervention: Preventing Maternal Risk for Gestational Diabetes Mellitus
}

\author{
Noraliza Radzali, Rosnah Sutan \\ Community Health Department, Medical Faculty, Universiti Kebangsaan Malaysia, \\ Kuala Lumpur, Malaysia \\ Email: rosnah_sutan@yahoo.com
}

Received 11 February 2016; accepted 4 April 2016; published 7 April 2016

Copyright (C) 2016 by authors and Scientific Research Publishing Inc. This work is licensed under the Creative Commons Attribution International License (CC BY). http://creativecommons.org/licenses/by/4.0/

\section{Abstract}

This study is aimed to evaluate the effectiveness of an intensive lifestyle counselling (ILC) designed to prevent gestational diabetes mellitus (GDM) among high risk mothers. A quasi-experimental trial was conducted in four selected health clinics (two clinics for intervention and two clinics for control) in Negeri Sembilan, Malaysia. Of the 320 subjects recruited, 148 respondents in the intervention group and 150 respondents in the control group had completed the study (response rate $93.1 \%$ ). The intervention group was given a routine antenatal care (RC) and a package of structured ILC sessions on diet, physical activity (PA) and information on appropriate gestational weight gain (GWG) in five routine antenatal care visits until 39 weeks' gestation. The controls received only the RC. Both groups are comparable for sociodemographic characteristics $(p<0.05)$. GDM incidence is higher in control group (16.7\%) compared to intervention group $(6.1 \%), p=$ 0.046. After controlling the covariates, the intervention group consistently showed protective for developing GDM, (aOR: 0.25, CI: $0.18-0.23, p=0.003$ ). The intervention group had significantly increased in PA (moderate intensity) mean score $(660.3 \pm 289.4 \mathrm{Met} / \mathrm{min})$ compared to control group $(571.36 \pm 230.38 \mathrm{Met} / \mathrm{min}), \mathrm{F}(1,296)=10.418, \mathrm{p}<0.001$ and comply to dietary recommendation ( $50.7 \%$ in intervention versus $16.7 \%$ in control), $p<0.001$. Total GWG significantly lesser in intervention $(11.4 \pm 2.5 \mathrm{Kg})$ than the control group $(12.7 \pm 2.9 \mathrm{Kg}), \mathrm{p}<001$. An ILC can reduce GDM incidence, by increasing $P A$, increase compliance to the dietary intake recommendation and lesser total GWG among high risk mothers.

\section{Keywords}

Lifestyle Counselling, GDM, Physical Activity, Dietary Intake, Gestational Weight Gain 


\section{Introduction}

The prevalence of diabetes and obesity has reached epidemic proportionsand became major public health concerns worldwide. In Malaysia, according to 3rd National Health Morbidity Survey (NHMS III) study, the incidence of Type 2 Diabetes Mellitus (T2DM) and obesity are increasing in all age groups, all racial groups among both sexes [1]. Globally, the incidence of Gestational Diabetes Mellitus (GDM) is rising, paralleling the rises in T2DM and obesity prevalence [2]. The prevalence of GDM among adults reproductive age above 30 years in Malaysia had arisen from 8.3\% in 1996 to $14.9 \%$ in 2006 [3]. Scientific evidence has shown that GDM women are at increased risk of developing obesity and T2DM [4]. Hence, it is crucial to identify women with GDM or those at risk for GDM as a target group to implement strategies to delay or prevent T2DM onset. Systematic review study has shown that up to 50\% of women who have had GDM will develop diabetes in subsequent pregnancy [5]. It has been projected that, women with a history of GDM are increased markedly in the first 5 years after delivery to develop T2DM [5].

GDM is defined as any degree of glucose intolerance with onset or first recognition during pregnancy and it is associated with short and long term morbidity in both mother and child [6]. Adverse infant outcomes include macrosomia, hypocalcemia, erythemia, hypoglycemia, jaundice, and birth trauma [6]. Later in life, these children are more likely to become obese, have an abnormal glucose tolerance, and develop diabetes in early adulthood [7]. GDM increases the mother's risk of hypertensive disorders during pregnancy, Caesarean delivery [8] and metabolic syndrome later in life [9].

Maternal and infant morbidity in the presence of GDM are highly associated with modifiable factor such as unhealthy lifestyle [10]. Exercise during confinement halved the risk of GDM among obese women [11]. Pregnant women who are physically active within the first 20 weeks in their pregnancy were noticed unlikely to develop GDM by halved [12]. Solomon et al. reported that women who engaged in vigorous activity or brisk walking at pre pregnancy stage were less likely to develop GDM [13]. Many studies have demonstrated that moderate intensity of physical activity during pregnancy with recommended duration of 30 minutes or more on most days of the week [14], is safe [15] and associated with good pregnancy outcome [16]. While, not physically active pregnant women were highly associated with GDM risk [17]. Evidences have suggested that both diet and physical activity altered the increase in insulin resistance especially during mid and late pregnancy [18]. Therefore, behavioural interventions were important to promote pregnant women practicing healthy diet in order to prevent subsequent obesity and GDM [19]. Saldana et al. found that there is significant asssociation between high saturated fat diet intake and glucose intolerance in pregnant women [20]. While taking high fibre diet will have protective effect in preventing GDM incidence [21] [22]. Physical activity and appropriate diet may prevent excessive gestational weight gain [23] and thus is crucial for dissevering the bound involving GDM, obesity and diabetes [24]. Three previous studies aimed at preventing excessive gestational weight gain [25]-[27] showed excessive gestational weight gain was prevented among the low-income or subgroups of normal-weight pregnant women.The information on weight gain in pregnancy as recommended by Institute of Medicine (IOM) in 2009, has been used in antenatal care monitoring [28].

Lifestyle interventions have been proven to reduce diabetes risk [9] [12] [17]. Therefore, identifying women at high risk of GDM will provide an excellent opportunity for proper intensive life style intervention [17]. The objective of this study was to assess the effectiveness of intensive and structured program on lifestyle counselling based on 3 components; physical activity, appropriate diet, and monitoring on gestational weight gain as recommended by IOM through intergration in an antenatal clinic follow up. The main hypothesis of this study stated: there is a significant difference between intervention and control groups in incidence of GDM, excessive gestational weight gain, comply to diet intake and physical activity as recommended.

\section{Methodology}

\subsection{Setting and Study Design}

This study was approved by Ethical Committee University Kebangsaan Malaysia Medical Centre and National Medical Research Review and was funded through a grant from a Universiti Kebangsaan Malaysia medical Centre (UKMMC) funding. This is a Quasi-Experimental study among high risk GDM antenatal mothers at two selected intervention clinics using intensified lifestyle counseling (ILC) and two control clinics using routine standard practice (RC). The study was conducted in Negeri Sembilan, Malaysia as it has shown increase in Diabetes melitus reported by National Health Morbidity Survey over a decade in 2011 [1]. All clinics 
are situated in Seremban district of Negeri Sembilan were chosen purposively based on increasing incidence of GDM and highest number of antenatal cases' attendance per annum. The recruitment of subjects started from September 2013 until November 2014. In the ILC, the subjects received intensive lifestyle counseling delivered by the nutritionist while in the RC the subjects received routine standard practice counseling. Five sessions of counseling were conducted during antenatal visits starting from 12 - 14 weeks gestation until 37 - 39 weeks gestation. The counseling were held in the health education room.

\subsection{Sampling Method}

The subjects selected were all pregnant women with the presence of at least two risk factors for GDM (BMI > $27 \mathrm{~kg} / \mathrm{m}^{2}$, previous macrosomic baby weighing $4 \mathrm{~kg}$ or above, previous GDM, first-degree relative with diabetes, glycosuria at the first prenatal visit and maternal age above 25 years old). The screening method was done using the $75 \mathrm{~g}$ Oral Glucose Tolerance Test (OGTT) and was performed at 12 weeks of gestation amongst these high risk GDM mothers. The OGTT results is normal if the fasting plasma glucose $\leq 5.6 \mathrm{mmol} / \mathrm{L}$ and 2-hour plasma glucose $\leq 7.8 \mathrm{mmol} / \mathrm{L}$ and any reading above this value will be diagnosed as GDM as per Ministry of Health, Malaysia's Guidelines for GDM. The inclusion criteria for inception recruitment of both groups were 1) normal OGTT, 2) antenatal care established at $<12$ weeks period of amenorrhea (POA), 3) able to read and write in Malay or English language 4)willing to participate voluntarily with written consentand d) Malaysian nationality. Exclusion criteria were; 1) twin/multiton pregnancy 2) pre-existing Diabetes Mellitus 3) patients whom participating in another recent study, 4) subjects with current obstetric complications (yellow and red colour coded maternity card), and e) suffering from any other medical illness.

Each of eligible subjects in both intervention and control clinic were explained about the study in brief by the research assistant (nurse) during recruitment phase (first antenatal care visit). Figure 1 shows that after obtaining informed consent from these subjects, the control groupreceived RC in the second antenatal care visit, including an initial physical examination and OGTT. During subsequent antenatal routine visits for control group, the RC was delivered focusing on diet and exercise during pregnancy as in Standard Operating Procedure for Pre-Diabetes by Division of Dietitian, Ministry of Health, Malaysia (2011). At each routine antenatal visit the weight was measured using a Seca 700 mechanical beam medical scale and recorded in the antenatal home based card.

The intervention group underwent a complete history and physical examination (at first antenatal care visit) with specific attention paid to pre-pregnancy weight, current weight, height and body masss index (BMI). At the second visit, and subsequent visits (all five sessions) the intervention group met with a nutritionist to receive ILC that included information on three main component (pregnancy healthy diet, appropriate physical activity choices and appropriate weight gain during pregnancy using the IOM guidelines). The content of diet advice follows Malaysian Dietary Guidelines, Recommended Nutrititional Intake for Malaysia in 2005 [29]. The five sessions of intensive lifestyle counselling sessions were planned at period of gestation 12 - 14 weeks, 16 - 18 weeks, 22 - 24 weeks, 26 - 28 weeks and 32 - 34 weeks. At the beginning of firstcounselling session, the baseline questionnaire which covered and assessed the sociodemographic factors, reproductive factors, current dietary habits Food Frequency Questionnaire (FFQ) and Pregnancy Physical ActivityQuestionnaire (PPAQ) of the subjects. The intervention group received counselling on 3 components; dietary intake, physical activity and recommendation of weight gain. After comparing the personal habits to the recommendations, the nutritionist assessed and planned the need for dietary changes, modify lifestyle based on identified barriers. Each subjects received a structured take home leaflet on physical activity and healthy diet during pregnancy at each visit.

The sample size is calculated based on effect size of recent study by Luotto et al. [17] that showed 30\% - 35\% of pregnant women in control group gaining weight within IOM guidelines and $25 \%$ - 55\% of pregnant women in the intervention group gaining weight within the IOM guidelines. Using Fleiss JL formula [30], 90\% power and an alpha of 0.05 , the required sample calculated was 132 subjects in each arm. However we added another $20 \%$ to encounter drop out rate, hence the sample needed for each arm was 160 subjects. The primary outcome was the incidence of GDM. The secondary outcomes were proportion of subjects gaining weight within the BMI specific recommendations by IOM 2009) [27], proportion of subject comply to the Recommended Nutritional Intake (RNI) [29] and physical activity. Body weight and pregnancy data such as incidence of GDM were obtained from the home based card. Body weight was measured in light clothing and without shoes at every maternity care visit using Seca beam scale. While, the height was measured with standardised stadiometer 


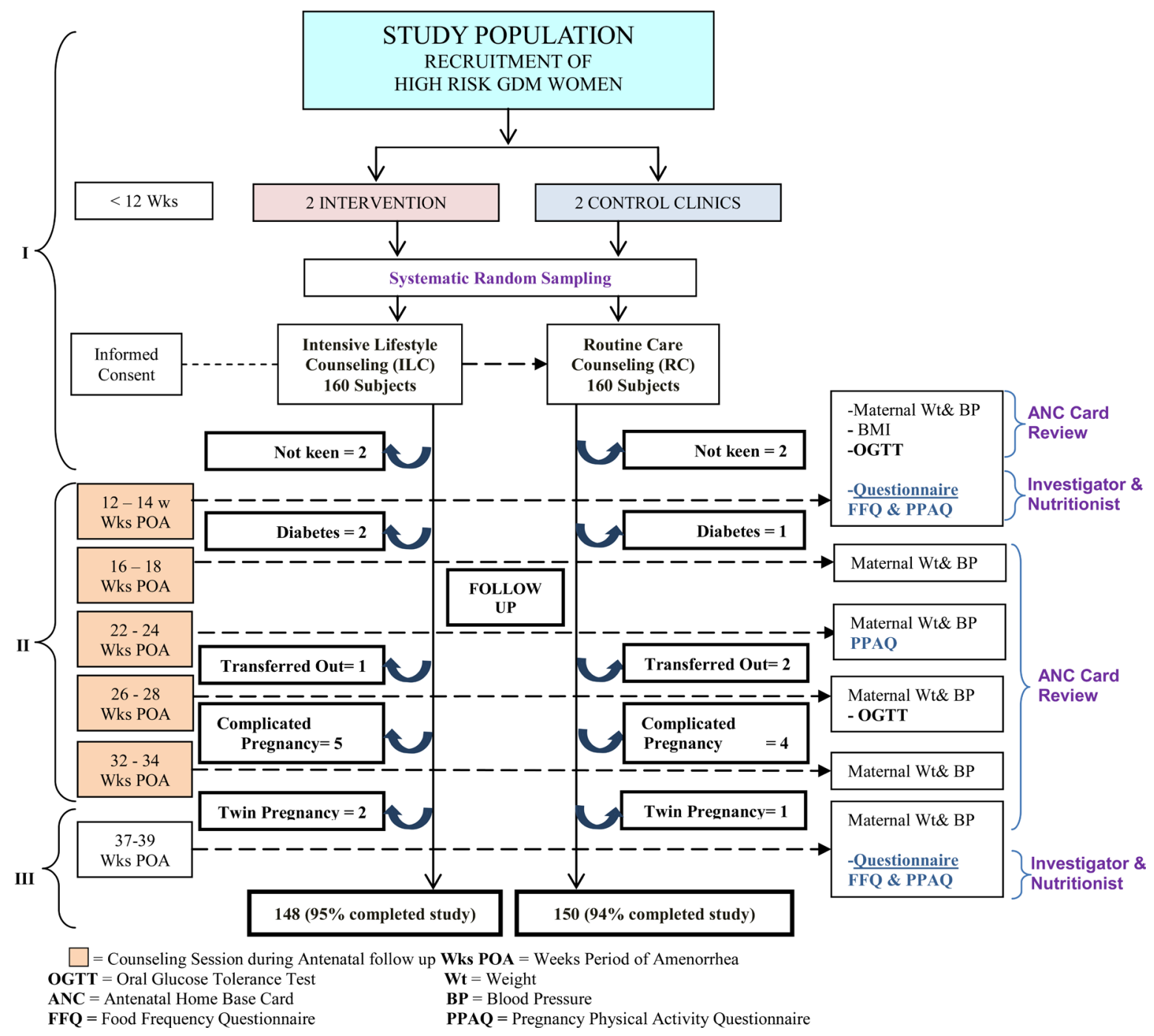

Figure 1. Study flow chart.

during the first visit only. The scales were calibrated through out the study. Baseline information on age, weight, height, BMI, education level and occupation were collected in both groups. These demographic characteristics were described using per cents, frequencies, means and standard deviations. Potential differences between the two groups (intervention and control) were analysed using Chi square tests and t-tests. A p value of less than 0.05 was used to define statistical significance in all cases. All analyses were performed using Statistical Package for the Social Sciences 21.

\subsection{Intervention Package}

\subsubsection{Diet}

For diet component of counselling, the food calory intake was calculated based on RNI [29] and the food pyramid for Malaysian. According to pregnancy stages, the goals component of the diet used in the intervention group as follow; total energy intake within RNI, carbohydrate 50 - 55 energy per cent (E\%), fat $<30 \mathrm{E} \%$ and protein $15-20 \mathrm{E} \%$. The food parameter was measured twice, at the baseline before intervention and after completion of five sessions of intensive lifestyle counseling. The dietary intake data that obtained from the respondents' FFQ were calculated manually by the nutritionist using standard manual food atlas for Malaysian. Women who were compliance to the dietary advice were defined as those who achieved at least two out of four goals. Women were encouraged to eat a diet rich in vegetables and fruits, and to use low-fat dairy products, low-fat 
meat, vegetable oils and wholegrain products.

\subsubsection{Physical Activity}

The respondents' physical activities data that obtained from the PPAQ was based on the amount of their time spent in 32 activities including household/caregiving, occupational, sports/exercise, and inactivity during the current trimester. The duration of time spent in each activity (moderate intensity) is multiplied by its intensity to arrive at a measure of average weekly energy expenditure (MET-h-week-1) attributable to each activity. Those with sedentary lifestyle were advised to have three times a week of continuous exercise for 15 minutes [31] and increasing gradually to four times a week for 30 minute sessions [32]. Recommendable types of exercise were brisk walking, swimming, Nordic walking, and antenatal exercise [33]. Compliance to recommended moderate intensity physical activity was those subjects who achieved at least $600 \mathrm{Met} / \mathrm{min}$ per week.

\subsubsection{Gestational Weight Gain}

The subjects were taught to monitor body weight gain at each antenatal visits as recorded in the antenatal home based card. The accepted gestational weight gain as recommended (stated in the antenatal home base card) is 0.5 $\mathrm{kg}$ per month for the first 5 months of pregnancy and $0.5 \mathrm{~kg}$ per week for remaining pregnancy period. Adherance to IOM guidelines were those subjects who complied to the recommended total gestational weight gain [27].

The nutritionists were trained about the counselling method which is based on transtheoretical model (TTM) by Prochaska et al. [34]. For each specific changes in subjects behaviour towards dietary intake and physical activity during pregnancy were mapped on TTM stages (pre-contemplation, contemplation, preparation, action and maintainance). Those who were dropped out and missed the counselling appointment, home visit will be made for the counselling. In this study, there was low dropped out rate.

\section{Results}

There were 320 eligible women (160 subjects in each arm)from selected intervention and control clinics. In intervention clinics, 160 eligible women were recruited, of these consented subjects, 12 women were excluded and there were only 148 (93\%) women were included in this intervention group. All subjects in intervention group were involved in physical activity and dietary counselling sessions. However, of these 160 subjects recruited in control clinics, 10 women were excluded and it is estimated that 150 subjects (94\%) in the control group participated in this study. Therefore, a total of 298 women in both intervention and control group completed the study and were available for analysis which showed that there were no statistically significant difference seen in baseline demographic composition and clinical examinations between the intervention and control group as shown in Table 1.

The results as in Table 2 showed that there is significant association between GDM incidence and study groups. Intervention group that received ILC had lower incidence of GDM, 9 subjects (6.1\%) as compared to control group that received RC, 25 subjects(16.7\%), $\left(\chi^{2}=0.80, p=0.004\right)$. Further analysis with simple logistic regression analysis showed the predictors of GDM. The results presented that intervention group showed 3 times protected from the risk of GDM incidence (crude OR: 0.32, 95\%CI: $0.17-0.72, \mathrm{p}=0.006$ ) as compared to control group, glycosuria showed 5 times risk of GDM (crude OR: 4.99, 95\%CI: $2.22-11.24$, p < 0.01), while previous GDM showed 4 times risk of GDM in current pregnancies (crude OR: 3.88, 95\%CI: 1.86 - 8.10, p < 0.01). However, after controlling covariates and confounders, it was found that control group persistently showed protective effect, 4 times protected from the risk of GDM incidence compared to intervention group (adjusted odds $0.25,95 \% \mathrm{CI}$ : $0.18-0.53, \mathrm{p}=0.003$ ). It means that the intervention has reduced the GDM incidence as four times.

The secondary study outcomesshowed that the intervention group gained significantly lesser total weight gain (11.39 \pm 2.52$)$ compared to control group $(12.69 \pm 2.88), \mathrm{p}<0.01$. The compliance rate of adherence to IOM guidelines was found higher in the intervention group. The predictor for recommended total weight gain during pregnancy were determined by factors adherence to IOM. Analysis using simple logistic regression found significant finding on pre-pregnancy BMI. Among the BMI classification, women with normal weight (BMI < 25) were more likely to adhere to the IOM guidelines. For example among all respondents in intervention group, 73.4\% normal weight women were adherence to IOM guidelines as compared to overweight women (17.4\%) and obese women (9.2\%), $\mathrm{p}<0.01$. While among all women in control group, $80.3 \%$ were normal weight women who adherence to IOM guidelines as compared to overweight women (17.4\%) and obese women (9.2\%), 
Table 1. Demographic and clinical characteristics of women in intervention and control group.

\begin{tabular}{|c|c|c|c|c|c|c|}
\hline Factor & & $\begin{array}{c}\text { Intervention } \\
\mathrm{n}=148\end{array}$ & $\begin{array}{l}\text { Control } \\
\mathrm{n}=150\end{array}$ & $\begin{array}{l}\text { Bivariate } \\
\text { Analysis }\end{array}$ & $\mathbf{p}$ & $\begin{array}{c}\text { Mean } \\
\text { difference }\end{array}$ \\
\hline \multirow{2}{*}{ Age } & $25-35$ years & 127 (85.8\%) & $123(82.0 \%)$ & $0.80^{\#}$ & 0.371 & \\
\hline & $>35$ years & $21(14.2 \%)$ & 27 (18.0\%) & & & \\
\hline \multirow{4}{*}{ Ethnicity } & Malay & $123(83.1 \%)$ & $129(86.0 \%)$ & $0.54^{\#}$ & 0.763 & \\
\hline & Chinese & $8(5.4 \%)$ & $6(4.0 \%)$ & & & \\
\hline & Indian & 17 (11.5\%) & $15(10.0 \%)$ & & & \\
\hline & Primary & $5(3.4 \%)$ & $7(4.7 \%)$ & $1.76^{\# \#}$ & 0.414 & \\
\hline \multirow[t]{2}{*}{ Education Level } & Secondary & 79 (53.4\%) & 89 (59.3\%) & & & \\
\hline & Tertiary & $64(43.2 \%)$ & $54(36.0 \%)$ & & & \\
\hline \multirow{3}{*}{ Occupation } & Non Working & $23(15.5 \%)$ & $28(18.7 \%)$ & $0.51^{\#}$ & 0.474 & \\
\hline & Working & $125(84.5 \%)$ & $122(81.3 \%)$ & & & \\
\hline & $<$ RM 3000 & $67(45.3 \%)$ & $63(42.0 \%)$ & $0.54^{\#}$ & 0.762 & \\
\hline \multirow[t]{2}{*}{ Household Income } & RM3000 - 5000 & $54(36.5 \%)$ & $56(37.3 \%)$ & & & \\
\hline & >RM 5000 & 27 (18.2\%) & $31(20.7 \%)$ & & & \\
\hline GDM Incidence $>24$ wks POA & $\begin{array}{l}\text { Yes } \\
\text { No }\end{array}$ & $\begin{array}{c}9(6.1 \%) \\
139(93.9 \%)\end{array}$ & $\begin{array}{c}25(16.7 \%) \\
125(83.3 \%)\end{array}$ & $8.26^{\#}$ & 0.004 & \\
\hline \multirow{2}{*}{$\begin{array}{c}\text { Blood Sugar Level }(\mathrm{mmol} / \mathrm{L})<12 \text { wks } \\
\text { POA (mean } \pm \text { sd })\end{array}$} & FBS & $4.4 \pm 0.34$ & $4.5 \pm 0.59$ & $1.31^{*}$ & 0.190 & 0.07 \\
\hline & 2HPG & $5.5 \pm 0.60$ & $5.7 \pm 1.34$ & $1.53^{*}$ & 0.126 & 0.18 \\
\hline \multirow{2}{*}{$\begin{array}{c}\text { Blood Sugar Level }(\mathrm{mmol} / \mathrm{L})>24 \text { wks } \\
\text { POA }(\text { mean } \pm \text { sd) }\end{array}$} & FBS & $4.72 \pm 0.72$ & $4.96 \pm 0.85$ & $2.679^{*}$ & 0.008 & 0.25 \\
\hline & 2HPG & $6.01 \pm 1.23$ & $6.44 \pm 1.62$ & $2.543^{*}$ & 0.011 & 0.43 \\
\hline \multirow{2}{*}{ Blood Pressure mmHg (mean \pm sd) } & Systolic & $117.6 \pm 7.55$ & $119.4 \pm 8.74$ & $1.87^{*}$ & 0.062 & 1.77 \\
\hline & Diastolic & $73.3 \pm 4.82$ & $73.4 \pm 4.89$ & $0.30^{*}$ & 0.763 & 0.17 \\
\hline Pre-pregnancy weight $(\mathrm{kg})($ mean \pm sd) & & $61.8 \pm 12.33$ & $62.1 \pm 12.14$ & $0.20^{*}$ & 0.844 & 0.28 \\
\hline Pre-pregnancy BMI (kg) (mean \pm sd) & & $25.1 \pm 4.99$ & $25.5 \pm 4.60$ & $0.67^{*}$ & 0.504 & 0.45 \\
\hline
\end{tabular}

${ }^{*}$ = t test; ${ }^{\#}$ = Chi square; ${ }^{\# \#}=$ Fisher; BMI = Body Mass Index; FBS = Fasting Blood Sugar; $2 \mathrm{HPG}=2$ Hour Plasma Glucose; wks POA = Weeks Period of Amenorrhhea.

Table 2. Factors in determining GDM risk (bivariate and multivariate logistic regression).

\begin{tabular}{|c|c|c|c|c|c|c|c|c|}
\hline Factor & $\begin{array}{c}\text { Yes } \\
\text { n (\%) }\end{array}$ & $\begin{array}{c}\text { No } \\
\text { n (\%) }\end{array}$ & $\chi^{2}$ & Crude OR 95\% CI & $\mathbf{p}$ & B & Adjusted OR 95\% CI & $\mathbf{p}$ \\
\hline GDM Incidence & & & 8.259 & & & & & 0.004 \\
\hline Control & 25 (16.7) & 125 (83.3) & & & & & & \\
\hline Intervention & $9(6.1)$ & 139 (93.9) & & & & & & \\
\hline \multicolumn{9}{|l|}{ Group } \\
\hline Control & & & 1.00 & & & & & \\
\hline Intervention & & & 7.648 & $0.324(0.17 ; 0.72)$ & 0.006 & -1.390 & $0.249(0.18 ; 0.53)$ & 0.003 \\
\hline \multicolumn{9}{|l|}{ Age } \\
\hline 25 - 35 years & & & 1.00 & & & & & \\
\hline$>35$ years & & & 0.575 & $1.50(0.50 ; 4.48)$ & 0.467 & & & \\
\hline \multicolumn{9}{|l|}{ Education Level } \\
\hline High & & & 1.00 & & & & & \\
\hline Low & & & 4.276 & $1.79(1.18 ; 6.66)$ & 0.060 & & & \\
\hline \multicolumn{9}{|l|}{ Ethnic } \\
\hline Non Malay & & & 1.00 & & & & & \\
\hline
\end{tabular}




\begin{tabular}{|c|c|c|c|c|c|c|}
\hline Continued & & & & & & \\
\hline Malay & 0.836 & $1.54(0.25 ; 2.24)$ & 0.345 & & & \\
\hline \multicolumn{7}{|l|}{ Occupation } \\
\hline Working & 1.00 & & & & & \\
\hline Non-working & 0.313 & $1.29(0.53 ; 3.16)$ & 0.569 & & & \\
\hline \multicolumn{7}{|c|}{ Household Income } \\
\hline High & 1.00 & & & & & \\
\hline Low & 3.735 & $2.03(0.98 ; 4.20)$ & 0.056 & & & \\
\hline \multicolumn{7}{|l|}{ Parity } \\
\hline Primi para & 1.00 & & & & & \\
\hline Multipara & 0.752 & $1.53(0.57 ; 4.13)$ & 0.405 & & & \\
\hline \multicolumn{7}{|c|}{ Previous Big baby } \\
\hline No & 1.00 & & & & & \\
\hline Yes & 1.284 & $1.51(0.74 ; 3.10)$ & 0.256 & & & \\
\hline \multicolumn{7}{|l|}{ Glycosuria } \\
\hline No & 1.00 & & & & & \\
\hline Yes & 13.429 & $4.99(2.22 ; 11.24)$ & $<0.001$ & 1.663 & 5.276 (2.03; 13.69) & 0.001 \\
\hline \multicolumn{7}{|l|}{ Previous GDM } \\
\hline No & 1.00 & & & & & \\
\hline Yes & 13.274 & 3.88 (1.86; 8.10) & $<0.001$ & 1.305 & $3.686(1.62 ; 8.40)$ & 0.002 \\
\hline \multicolumn{7}{|c|}{ Close RelativesDM } \\
\hline No & 1.00 & & & & & \\
\hline Yes & 0.824 & $1.65(0.59 ; 4.63)$ & 0.344 & & & \\
\hline \multicolumn{7}{|l|}{$\mathrm{BMI} \geq 27$} \\
\hline No & 1.00 & & & & & \\
\hline Yes & 0.020 & $1.07(0.42 ; 2.74)$ & 0.886 & & & \\
\hline
\end{tabular}

$\mathrm{p}<0.01$ (Table 3).

Based on ANOVA Two-Way Repeated Measures analysis as in Table 4, explained that there is no difference in physical activity (moderate intensity) mean score at first trimester (baseline) between intervention group (602.46 Met/min, sd = 369.46) and control group (604.52 Met/min, sd = 251.20). However there is difference in physical activity mean score between these two groups at second trimester intervention group $(678.86 \mathrm{Met} / \mathrm{min}$, $\mathrm{sd}=306.38)$ and control group $(605.35 \mathrm{Met} / \mathrm{min}$, $\mathrm{sd}=251.19)$. At the third trimester, physical activity mean score is increased in intervention group (699.60 Met/min, sd = 192.37) but reduced in the control group (504.22 $\mathrm{Met} / \mathrm{min}$, sd $=188.75)$. There is a significant difference in total mean score of physical activity between intervention group (660.30, $s d=289.40$ ) and control group (571.36, $s d=230.38) ; \mathrm{F}(1,296)=10.418, \mathrm{p}=0.001$. ANOVA test (between subject found that study groups factor has significant main effect on physical activity level, $\mathrm{F}(1,296)=10.4, \mathrm{p}<0.01$, and the effect size is moderate (eta square value $=0.035$ ). While, ANOVA test (within subject) also showed that there is significant main effect of time factor on physical activity level, F(1.15, 340.89 ) $=33.19, \mathrm{p}<0.01$, and the effect size was small (eta squared $=0.023$ ). However, there is moderate interaction effect of two factors (time and study group) on physical activity level (eta squared $=0.101$ ).

Chi square test revealed that there is significant association between study groups and compliance to dietary intake recommendations (at least 2 out of 4 recommendations from RNI Malaysia guidelines). There were 75 respondents (50.7\%) in intervention groups are comply to diet recommendation as compared to 29 respondents (16.7\%) in control group, $\left(\chi^{2}=32.210, \mathrm{p}<0.01\right)$. T test showed (Table 5) that there is significant difference in total calories intake which is more in the control group $2290.70 \pm 183.03 \mathrm{kcal}$ as compared to intervention group $(2221.14 \pm 227.81) \mathrm{kcal}$ with $\mathrm{t}=2.555 ; \mathrm{p}=0.01$ There is also higher intake of diet containing fat amongst control group $30.67 \pm 3.70 \mathrm{E} \%$ compared to control group $28.65 \pm 4.12 \mathrm{E} \%, \mathrm{t}=4.445 ; \mathrm{p}<0.01$. However, there 
Table 3. Gestational weight gain (secondary outcome) and pre-pregnancy body mass index adherent to institute of medicine guidelines between study groups (post-intervention).

\begin{tabular}{|c|c|c|c|c|c|c|}
\hline \multicolumn{2}{|c|}{ Factor } & Intervention & Control & Bivariate Analysis & $\mathrm{p}$ & Mean Difference \\
\hline \multirow{2}{*}{\multicolumn{2}{|c|}{$\begin{array}{c}\text { Mean Total GWG (Kg), mean } \pm \text { sd } \\
\text { GWG Adherent to IOM, n(\%) }\end{array}$}} & $11.39 \pm 2.52$ & $12.69 \pm 2.88$ & $4.148^{*}$ & $<0.001$ & 1.3 \\
\hline & & & & & & \\
\hline & Yes & $109(73.6 \%)$ & $76(50.7 \%)$ & $16.715^{\#}$ & $<0.001$ & \\
\hline & No & $39(26.4 \%)$ & $74(49.3 \%)$ & & & \\
\hline \multicolumn{7}{|c|}{ Pre-pregnancy BMI (Kg/m²), n (\%) } \\
\hline \multirow{2}{*}{$\begin{array}{c}\text { Normal } \\
(\mathrm{BMI}<25)\end{array}$} & Yes & $80(73.4 \%)$ & $61(80.3 \%)$ & $55.298^{+}$ & $<0.001^{+}$ & \\
\hline & No & $2(5.1 \%)$ & $11(14.9 \%)$ & & & \\
\hline \multirow{2}{*}{$\begin{array}{c}\text { Overweight } \\
\text { (BMI } 25 \text { - 29.9) }\end{array}$} & Yes & $19(17.4 \%)$ & $12(15.8 \%)$ & & & \\
\hline & No & $20(51.3 \%)$ & $38(51.4 \%)$ & $65.513^{0}$ & $<0.001^{0}$ & \\
\hline \multirow{2}{*}{$\begin{array}{c}\text { Obese } \\
(\mathrm{BMI}>30)\end{array}$} & Yes & $10(9.2 \%)$ & $3(3.9 \%)$ & & & \\
\hline & No & $17(43.6 \%)$ & $25(33.8 \%)$ & & & \\
\hline
\end{tabular}

GWG = Gestational Weight Gain; BMI = Body Mass Index; IOM = Institute of Medicine, America; ${ }^{*}=$ Chi square $^{*}=\mathrm{t}$ test; ${ }^{0}=\mathrm{Control}$ group; ${ }^{+}=$ Intervention group.

Table 4. ANOVA-2 way repeated measures analysis on physical activity (moderate intensity) between intervention and control group (post-intervention).

\begin{tabular}{|c|c|c|c|c|c|c|}
\hline \multirow[t]{2}{*}{ Physical Activity (Met/min) } & \multicolumn{2}{|c|}{ Intervention Group $(n=148)$} & \multicolumn{2}{|c|}{ Control Group $(n=150)$} & \multirow[t]{2}{*}{ F (df) } & \multirow[t]{2}{*}{$\mathbf{p}$} \\
\hline & mean & \pm sd & mean & $\pm \mathrm{sd}$ & & \\
\hline Total mean & 660.30 & 289.40 & 571.36 & 230.38 & $10.418(1,296)$ & 0.001 \\
\hline Trimester 1 & 602.46 & 369.46 & 604.52 & 251.20 & & \\
\hline Trimester 2 & 678.86 & 306.38 & 605.35 & 251.19 & & \\
\hline Trimester 3 & 699.60 & 192.37 & 504.22 & 188.75 & & \\
\hline
\end{tabular}

sd = standard deviation.

Table 5. Comparison of dietary intake between intervention and control group (post-intervention).

\begin{tabular}{|c|c|c|c|c|c|c|c|}
\hline \multirow{2}{*}{ Factor } & \multicolumn{2}{|c|}{ Intervention Group $(n=148)$} & \multicolumn{2}{|c|}{ Control Group $(n=150)$} & \multirow{2}{*}{$\mathrm{t}$} & \multirow{2}{*}{$\mathrm{p}$} & \multirow{2}{*}{$\begin{array}{c}\text { Mean } \\
\text { Difference }\end{array}$} \\
\hline & mean & $\pm s d$ & mean & $\pm s d$ & & & \\
\hline Total calory (kcal) & 2221.14 & 277.81 & 2390.70 & 183.03 & 2.555 & 0.01 & 69.554 \\
\hline Carbohydrate (E\%) & 51.54 & 1.41 & 51.77 & 1.45 & 1.412 & 0.159 & 0.234 \\
\hline Protein (E\%) & 20.01 & 2.02 & 19.80 & 1.99 & 0.877 & 0.331 & 0.204 \\
\hline Fat (E\%) & 28.65 & 4.12 & 30.67 & 3.70 & 4.445 & $<0.001$ & 2.016 \\
\hline
\end{tabular}

$\mathrm{t}=\mathrm{t}$ test; $\mathrm{sd}=$ standard deviation; $\mathrm{E} \%$ = Energy percent.

is no significance difference in carbohydrate and protein intake between these two groups.

\section{Discussion}

Our study showed that there was less incidence of GDM in intervention group (6.1\%) as compared to control group (16.7\%). This finding similar with the study done by Hu et al. which randomized 404 participants diagnosed with GDM from 2005 to 2009 to either a lifestyle intervention or a control group [28] and the results indicated that women in the intervention group had a greater reduction in plasma insulin levels $(11.8 \pm 27.4 \mathrm{pmol} / \mathrm{l})$ as compared to those in the control arm $(3.2 \pm 31.2 \mathrm{pmol} / \mathrm{l}, \mathrm{p}=0.004)$. While a study by Shyam et al. observed a positive impact of the intervention on fasting glucose levels by among 77 Asian women who had been diagnosed with GDM using low glycemic index dietary intervention [35]. Their study showed that 6 months of follow-up, the intervention group had significantly decreases in 2-h post-prandial blood glucose after a 75-g oral glucose tolerance test $(2.8 \mathrm{mmol} / \mathrm{l})$ as compared to the control arm $(2.0 \mathrm{mmol} / \mathrm{l}), \mathrm{p}=0.025$ [35]. 
Intensive lifestyle counselling in our study has significantly lesser total gestational weight gain in intervention as compared to control groups. The intervention showed a significant difference in the rate of adherence to IOM guidelines. Our study has similar findings with intervention study done by Asbee et al. [36]. That study found that higher pre-pregnancy BMI would have less adherences to IOM guidelines and risk for excessive gestational weight gain [36]. Our study supported earlier findings found by Polley et al. \& Kinnunen et al. who gave structured counselling and education about healthy eating, appropriate exercise and proper weight gain [25] [37]. Their study showed that there was a reduction of percentage of women who gained weight more than the IOM recommendations in the intervention group compared to controls. Another study by Olson et al. \& Mamun et al. found that an intervention by health education program delivered by healthcare provider via mail had significantly reduced excessive weight gain amongst low income subgroup [27] [38].

Our lifestyle intervention has significantly reduced the total fat intake and calories intake among respondents in intervention group as compared to control group. Our study result has similar findings with four trials done recently that examined the impact of the lifestyle intervention on diet by Hu Gang et al. in 2012; Shyam et al. in 2013; Ferrara et al. in 2011 and Reinhardt et al. in 2012 which observed a statistically significant beneficial effect on one or more dietary components [28] [35] [39] [40]. For example, in the study by Ferrara et al., the result showed a significant mean difference in fat intake of 3.55\% between the lifestyle arm and the control arm ( $\mathrm{p}=$ 0.002) [39]. Hu et al. stated in their study that the lifestyle intervention group had $77.1 \%$ decrease in energy from fat as compared to a 68.9\% decrease in the control group $(\mathrm{p}=0.064)$ [28]. Reinhardt et al. in their 6-month pilot study among Australian women found a change in total fat between the arms of 19 g/day $(95 \%$ CI: 37, 1) [40]. A positive impact of the lifestyle intervention on dietary fiber intake was also detected by Hu et al. and Shyam et al. but not in our study [28] [35]. There was significantly positive impact of physical activity among respondents in intervention group as compared to control group in our study. Our study finding was similar with those three studies by Hu Gang et al. in 2012; Reinhardt et al. in 2012 \& Ratner et al. in 2008, which examined the impact of lifestyle intervention on physical activity among women diagnosed with GDM that observed a statistically significant impact on one or more measures of activity [28] [40] [41]. For example, in the trial by Reinhardt et al., the intervention group increased leisure physical activity compared to the control group by 11 min per day (95\% CI: 1, 22) [41]. Hu et al. found a similar beneficial impact on leisure-time physical activity, with an increase of $59.4 \%$ in the intervention group as compared to a $26.9 \%$ increase in the control group (p < 0.001) [28]. A trial by Ratner et al. showed an increase of approximately 1.5 hours per week in moderate-intensity physical activity after 1 year among respondents in the intervention group [41].

The strength of the study is mainly of its design, a quasi-experimental study. The questionnaires used were validated food frequency and physical activity questionnaire for pregnancy woman. This is a comprehensive intervention program consists of lifestyle counseling, health education, discussion and motivation support delivered by expert health personnel, nutritionists. Mode of delivering counseling intervention were through power point presentation, take home leaflet, diet and physical activity diary discussions. The intervention took place at existing health education room. This interventional study has low dropped out rate, and those who werenot able to attend for the counseling, a new appointment for counseling will be given through phone call or home visit. Our study has several limitations. Hawthorne effect may have occured, the repondents who involved in the intervention were counseled regarding recommended dietary intake, physical activity and weight gain during pregnancy would have more likely to give specific attention on this factors and would modify their behaviours accordingly. However there were few subjects who were not ready to change their risky behaviour in the beginning of intervention have had complicated the study. While information on pre-pregnancy body weight that was self reported will prone causing self-reported bias. Content bias would have occured too because we were unable to control content of the counseling delivered by the nutritionist to the subjects during each maternity visits although using the same intervention module.

An organized, consistent using a structured program tailored to society needs on lifestyle counselling able to reduce incidence of GDM through modifying potential risk behaviour. Therefore, it is important to counsel all women at risk of GDM during antenatal visit at primary health care on the importance of diet, physical activity and weight management. Concerted effort to organize dedicated team, implementing intensified lifestyle counseling program and sustainably run it can reduce the potential hazardous to mother and baby outcome. It is recommended pre pregnancy care clinic to do proper screening in identifying risk of pre pregnancy BMI and continue proper antenatal monitoring for good gestational weight gain in order to prevent GDM. The intensive lifestyle counseling package have shown effectiveness in prevention of GDM among high risk group. Therefore, 
this package should be disseminated to all health care provider in all healthcare centre.

\section{Acknowledgements}

The authors thank the Ethical Committee Universiti Kebangsaan Malaysia Medical Centre for funding this study. We thanks the staffs from District Health Office Seremban for technical assistance during data collection, the Medical Officer of Health District Seremban and the Nutritionist for helping us in intervention package assessment.

\section{References}

[1] National Health Morbidity Survey III. Institute for Public Health, National Institutes of Health and Ministry of Health (2008) The Fourth National Health Morbidity Survey 2011. NHMS IV, 21-25.

[2] Anna, V., Van der Ploeg, H.P., Cheung, N.W., et al. (2008) Socio-Demographic Correlates of the Increasing Trend in Prevalence of Gestational Diabetes Mellitus in a Large Population of Women between 1995 and 2005. Diabetes Care, 31, 2288-2293. http://dx.doi.org/10.2337/dc08-1038

[3] Letchuman, G.R., Wan Nazaimoon, W.M., Wan Mohamad, W.B., Chandran, L.R., Tee, G.H., Jamaiyah, H., Isa, M.R., Zanariah, H., Fatanah, I. and Ahmad Faudzi, Y. (2010) Prevalence of Diabetes in the Malaysian National Health Morbidity Survey III. Medical Journal of Malaysia, 65, 180-186.

[4] World Health Organization (2000) Obesity: Preventing and Managing the Global Epidemic. World Health Organization, Geneva, 305-307.

[5] Kim, C., Newton, K. and Knopp, R. (2002) Gestational Diabetes and the Incidence of Type 2 Diabetes. Diabetes Care, 25, 1862-1868. http://dx.doi.org/10.2337/diacare.25.10.1862

[6] American Diabetes Association (2001) Gestational Diabetes Mellitus. Diabetes Care, 24, 77-79.

[7] Dorner, G., Plagemann, A., Neu, A. and Rosenbauer, J. (2000) Gestational Diabetes as Possible Risk Factor for Type 1 Childhood-Onset Diabetes in the Offspring. Neuroendocrinology Letters, 21, 355-359.

[8] Wendland, E.M., Torloni, M.R., Falavigna, M., Trujillo, J. and Dode, M.A. (2012) Gestational Diabetes and Pregnancy Outcomes-A Systematic Review of the World Health Organization (WHO) and the International Association of Diabetes in Pregnancy Study Groups (IADPSG) Diagnostic Criteria.BMC Pregnancy Childbirth, 12, 23. http://dx.doi.org/10.1186/1471-2393-12-23

[9] Kim, C. (2010) Gestational Diabetes: Risks, Management, and Treatment Options. Review. International Journal of Women's Health, 2, 339-351. http://dx.doi.org/10.2147/IJWH.S13333

[10] Smith, B.J., Cheung, N.W., Zehle, K., McLean, M. and Bauman, A.E. (2005) Post-Partum Physical Activity and Related Psychosocial Factors among Women with Recent Gestational Diabetes. Diabetes Care, 28, 2650-2654. http://dx.doi.org/10.2337/diacare.28.11.2650

[11] Dye, T.D., Knox, K.L., Artal, R., Aubry, R.H. and Wojtowycz, M.A. (1997) Physical Activity, Obesity, and Diabetes in Pregnancy. American Journal of Epidemiology, 146, 961-965.

[12] Dempsey, J.C., Sorensen, T.K., Williams, M.A., Lee, I.M., Miller, R.S., Dashow, E.E. and Luthy, D.A. (2004) Prospective Study of Gestational Diabetes Mellitus Risk in Relation to Maternal Recreational Physical Activity before and during Pregnancy. American Journal of Epidemiology, 159, 663-670. http://dx.doi.org/10.1093/aje/kwh091

[13] Solomon, C.G., Willett, W.C. and Carey, V.J. (1997) A Prospective Study of Pre-Gravid Determinants of Gestational Diabetes Mellitus. JAMA, 278, 1078-1083. http://dx.doi.org/10.1001/jama.1997.03550130052036

[14] ACOG (American College of Gynecologists) Committee (2002) Exercise during Pregnancy and the Postpartum Period. Obstetrics \& Gynecology, 99, 171-173.

[15] Barakat, R., Ruiz, J.R., Stirling, J.R., Zakynthinaki, M. and Lucia, A. (2009) Type of Delivery Is Not Affected by Light Resistance and Toning Exercise Training during Pregnancy: A Randomized Controlled Trial. American Journal of Obstetrics \& Gynecology, 201, 590-596.

[16] Barakat, R., Ruiz, J.R., Rodríguez-Romo, G., Montejo-Rodríguez, R. and Lucia, A. (2010) Does Exercise Training during Pregnancy Influence Fetal Cardiovascular Responses to an Exercise Stimulus? Insights from a Randomised, Controlled Trial. British Journal of Sports Medicine, 44, 762-764. http://dx.doi.org/10.1136/bjsm.2009.062547

[17] Luoto, R., Kinnunen, T.I., Aittasalo, M., Kolu, P., Raitanen, J., Ojala, K., et al. (2011) Primary Prevention of Gestational Diabetes Mellitus and Large-for-Gestational-Age Newborns by Lifestyle Counseling: A Cluster-Randomized Controlled Trial. PLoS Medicine, 8, e1001036. http://dx.doi.org/10.1371/journal.pmed.1001036

[18] Clapp, J.F. (2006) Effects of Diet and Exercise on Insulin Resistance during Pregnancy. Metabolic Syndrome and Related Disorders, 4, 84-90. http://dx.doi.org/10.1089/met.2006.4.84 
[19] Siega-Riz, A.M., Evenson, K.R. and Dole, N. (2004) Pregnancy-Related Weight Gain-A Link to Obesity? Nutrition Reviews, 7, 105-111.

[20] Saldana, T.M., Siega-Riz, A.M. and Adair, L.S. (2004) Effect of Macronutrient Intake on the Development of Glucose Intolerance during Pregnancy. The American Journal of Clinical Nutrition, 79, 479-486.

[21] Meyer, K.A., Kushi, L.H., Jacobs, D.R., Slavin, J., Sellers, T.A. and Folsom, A.R. (2000) Carbohydrates, Dietary Fibre and Incident Type II Diabetes in Older Women. The American Journal of Clinical Nutrition, 71, 921-930.

[22] Davenport, M.H., Mottola, M.F., McManus, R. and Gratton, R. (2008) A Walking Intervention Improves Capillary Glucose Control in Women with Gestational Diabetes Mellitus: A Pilot Study. Applied Physiology, Nutrition, and Metabolism, 33, 511-517. http://dx.doi.org/10.1139/h08-018

[23] Tobias, D.K., Zhang, C., Van Dam, R.M., Bowers, K. and Hu, F.B. (2011) Physical Activity before and during Pregnancy and Risk of Gestational Diabetes Mellitus: A Meta-Analysis. Diabetes Care, 34, 223-229. http://dx.doi.org/10.2337/dc10-1368

[24] Gray-Donald, K., Robinson, E., Collier, A., David, K., Renaud, L. and Rodrigues, S. (2000) Intervening to Reduce Weight Gain in Pregnancy and Gestational Diabetes Mellitus in Cree Communities: An Evaluation. Canadian Medical Association Journal, 163, 1247-1251.

[25] Polley, B.A., Wing, R.R. and Sims, C.J. (2002) Randomized Controlled Trial to Prevent Excessive Weight Gain in Pregnant Women. International Journal of Obesity and Related Metabolic Disorders, 26, 1494-1502. http://dx.doi.org/10.1038/sj.ijo.0802130

[26] Olson, C.M., Strawderman, M.S. and Reed, R.G. (2004) Efficacy of an Intervention to Prevent Excessive Gestational Weight Gain. American Journal of Obstetrics \& Gynecology, 191, 530-536. http://dx.doi.org/10.1016/j.ajog.2004.01.027

[27] Rasmussen, K.M. and Yaktine, A.L. (Eds.), Institute of Medicine (Committee to Reexamine IOM Pregnancy Weight Guidelines, Food and Nutrition Board and Board on Children, and Families) (2009) Weight Gain during Pregnancy: Reexamining the Guidelines. National Academy Press, Washington DC.

[28] Hu, G., Tian, H., Zhang, F., Liu, H., Zhang, C., Zhang, S., et al. (2012) Tianjin Gestational Diabetes Mellitus Prevention Program: Study Design, Methods, and 1-Year Interim Report on the Feasibility of Lifestyle Intervention Program. Diabetes Research and Clinical Practice, 98, 508-517. http://dx.doi.org/10.1016/j.diabres.2012.09.015 American Diabetes Association (2004) Gestational Diabetes Mellitus. Diabetes Care, 27, s88-s90.

[29] Recommended Nutritional Intake (RNI) for Malaysia (2005) Malaysian Nutritional Intake Guidelines.

[30] Fleiss, J.L. (1986) Analysis Data from Multiclinic Trials. Controlled Clinical Trials, 7, 267-275. http://dx.doi.org/10.1016/0197-2456(86)90034-6

[31] Bung, P., Bung, C., Artal, R., Khodiguian, N., Fallenstein, F. and Spätling, L. (1993) Therapeutic Exercise for Insulin-Requiring Gestational Diabetics: Effects on the Fetus Results of a Randomized Prospective Longitudinal Study. Journal of Perinatal Medicine, 21, 125-137. http://dx.doi.org/10.1515/jpme.1993.21.2.125

[32] Campbell, M.K. and Mottola, M.F. (2001) Recreational Exercise and Occupational Activity during Pregnancy and Birth Weight: A Case Control Study. American Journal of Obstetrics \& Gynecology, 184, 403-408. http://dx.doi.org/10.1067/mob.2001.109392

[33] Cheung, N.W. and Byth, K. (2003) The Population Health Significance of Gestational Diabetes. Diabetes Care, 26, 2005-2009. http://dx.doi.org/10.2337/diacare.26.7.2005

[34] Prochaska, J.O. (1996) A Stage Paradigm for Integrating Clinical and Public Health Approaches to Smoking Cessation. Addictive Behaviors, 21, 721-732. http://dx.doi.org/10.1016/0306-4603(96)00031-7

[35] Shyam, S., Arshad, F., Abdul Ghani, R., Wahab, N.A., Safii, N.S., Nisak, M.Y.B., Chinna, K. and Kamaruddin, N.A. (2013) Low Glycaemic Index Diets Improve Glucose Tolerance and Body Weight in Women with Previous History of Gestational Diabetes: A Six Months Randomized Trial. Nutrition Journal, 12, 68. http://dx.doi.org/10.1186/1475-2891-12-68

[36] Asbee, S.M., Jenkins, T.R., Butler, J.R., White, J., Elliot, M. and Rutledge, A. (2009) Preventing Excessive Weight Gain during Pregnancy through Dietary and Lifestyle Counseling: A Randomized Controlled Trial. Obstetrics \& Gynecology, 113, 305-312. http://dx.doi.org/10.1097/AOG.0b013e318195baef

[37] Kinnunen, T.I., Aittasalo, M., Koponen, P., Ojala, K., Mansikkamäki, K., Weiderpass, E., Fogelholm, M., et al. (2008) Feasibility of a Controlled Trial Aiming to Prevent Excessive Pregnancy-Related Weight Gain in Primary Health Care. BMC Pregnancy and Childbirth, 8, 37. http://dx.doi.org/10.1186/1471-2393-8-37

[38] Mamun, A.A., O’Callaghan, M., Callaway, L., Williams, G., Najman, J. and Lawlor, D.A. (2009) Associations of Gestational Weight Gain with Offspring Body Mass Index and Blood Pressure at 21 Years of Age: Evidence from a Birth Cohort Study. Circulation, 119, 1720-1727. http://dx.doi.org/10.1161/CIRCULATIONAHA.108.813436

[39] Ferrara, A., Hedderson, M., Albright, C., Ehrlich, S.F., Quesenberry Jr., C.P., Peng, T., et al. (2011) A Pregnancy and 
Postpartum Lifestyle Intervention in Women with Gestational Diabetes Mellitus Reduces Diabetes Risk Factors: A Feasibility Randomized Control Trial. Diabetes Care, 34, 1519-1525. http://dx.doi.org/10.2337/dc10-2221

[40] Reinhardt, J., Van Der Ploeg, H.P., Grzegrzulka, R. and Timperley, J.G. (2012) Implementing Lifestyle Change through Phone-Based Motivational Interviewing in Rural-Based Women with Previous Gestational Diabetes Mellitus. Health Promotion Journal of Australia, 23, 5-9.

[41] Ratner, R.E., Christophi, C.A., Metzger, B.E., Dabelea, D., Bennett, P.H., Pi-Sunyer, X., et al. (2008) Diabetes Prevention Program Research Group: Prevention of Diabetes in Women with a History of Gestational Diabetes: Effects of Metformin and Lifestyle Interventions. The Journal of Clinical Endocrinology \& Metabolism, 93, 4774-4779.

http://dx.doi.org/10.1210/jc.2008-0772 